\title{
CERVICAL PRIMING WITH SUBLINGUAL MISOPROSTOL PRIOR TO INSERTION OF AN INTRAUTERINE DEVICE IN WOMEN WITH NO PREVIOUS VAGINAL DELIVERY A RANDOMIZED CONTROLLED TRIAL
}

\author{
By
}

\author{
Ismail M. El-Garhy, Maged M. Labib* and Mohamed A. Galal \\ Departments of Obstetrics and Gynecology, Faculty of Medicine, Al-Azhar University and \\ El Maadi Armed Forces hospital* \\ Corresponding author: Mohamed A. Galal \\ Mobile: 01090983652, E-mail: $\underline{\mathrm{dr} \_ \text {mohamed_ali_galal@yahoo.com }}$
}

\begin{abstract}
Background: The use of misoprostol at a dose of $600 \mu \mathrm{g}$ administered sublingual 2 hrs prior to IUD insertion increased the ease of insertion and reduced the incidence of failed insertion and pain during the procedure, although the frequency of cramps increased following misoprostol use.

Objective: To evaluate the efficacy of sublingual misoprostol 2 hours prior to intrauterine device (IUD) insertion in women with previous cesarean section.

Patients and Methods: This randomized, double-blind clinical trial was conducted on women of reproductive age were submitted to IUD insertion between Jan 2019 and July 2019. A total of 120 women were randomly allocated to two equal groups: Group I received $600 \mu \mathrm{g}$ of misoprostol sublingual $2 \mathrm{~h}$ prior to IUD insertion, Group II received placebo.
\end{abstract}

Results: Significant differences were found between the groups for all the immediate end points studied, with less difficulty in inserting the IUD with misoprostol group. A positive balance was detected between the benefits and risks of the use of misoprostol. However, it was not feasible to conclude that its use was imperative prior to IUD insertion in previous CS, and IUD insertion should not be canceled when the medication was unavailable.

Conclusion: In view of its effect in promoting cervical dilatation, misoprostol may be used prior to IUD insertion in previous CS.

Key words: Sublingual 600 microgram misopristol prior to IUD insertion.

\section{INTRODUCTION}

Each year, more than 100 million of women make decisions about beginning contraception after child birth. Proper family planning programs and adequate methods of contraception are important tools to avoid many problems in our world (Zakiyah et al., 2019).
Intrauterine device insertion is an outpatient procedure that should be performed by trained healthcare professionals, It's an effective and increasingly popular form of reversible contraception (Mosher \& Jones, 2010 and Trussell et al., 2011). The increase in popularity has been attributed to their 
efficacy, ease of reversibility, and patient satisfaction, with minimal effort required for long-term use (Peipert et al., 2011).

Beside to vasectomy, they are the most cost-effective method of long-term contraception available in the United States (Trussell, 2010).

The IUDs currently available include the copper T380A IUD (Paraguard) and 2 levonorgestrel-releasing intrauterine systems (Mirena and Skyla). Insertion failures and cervical problems seem to occur more often among women who have never delivered vaginally (Daniels et al., 2015).

Cervical stenosis and a significantly ante- or retroverted position of the uterus, have been described as factors associated with a difficult sounding of the cervical canal or even failure to insert the IUD (Preutthipan and Herabutya, 2010).

Moreover, Preutthipan and Herabutya (2010) have shown the benefit of misoprostol as a cervical ripening agent in women with previous cesarean section.

The aim of this work was to evaluate the efficacy of sublingual misoprostol 2 hours prior to intrauterine device (IUD) insertion in women with previous cesarean section.

\section{PATIENTS AND METHODS}

This is a randomized controlled double blind study that was conducted at Obstetrics and Gynecology Department, El-Hawamdiya General Hospital during the period from Jan 2019 to July 2019.

The study included all women aged from 25 to 40 years with previous cesarean section and with no previous vaginal delivery attending outpatient clinic for IUD insertion during postpartum period (after puerperium).

While patients with contraindications for misoprostol use (pregnancy and prostaglandin allergy), contraindications for IUD use (gynecologic malignancy, pelvic inflammatory disease and unexplained vaginal bleeding), previous vaginal delivery and medical disorders as bleeding tendency were excluded from the study.

Participants were allowed to breastfeed provided that they left an interval of 4 hours between time of administration of misoprostol and breastfeeding.

Groups of study: 120 candidates for $\mathrm{Cu}$ $T$ 380A IUD insertion were enrolled in the study. They were divided into two groups: Group 1: Sixty women received 600 micrograms of misoprostol sublingual two hours before IUD insertion. Group 2: Sixty women received the placebo sublingual.

Placebo was the same in size, color and shape to misoprostol.

The placebo and misoprostol were put in 120 numbered closed envelopes according to the table of random numbers and an envelope was allocated to each patient accordingly.

Informed consent was taken from all women before participation in the study.

\section{Study procedures:}

All patients were subjected to the following:

\section{Complete history taking:}

Full history taking, obstetric history, menstrual history, medical history and 
data were collected in a special form for each patient.

\section{Proper counseling:}

Proper counseling of each patient about different types of IUDs, the advantage and side effects of each type, explanation of the menstrual pattern changes, assuring the patient that these changes are very common and that it will disappear after a period of time after insertion. Informed consent was taken from all patients.

\section{Examination:}

General, Abdominal and Pelvic examination. $600 \mathrm{ug}$ misoprostol (3 tablets Misotac ${ }^{\circledR}$ (Sigma Pharmaceutical Industries, Egypt) or Placebo were administered sublingual two hours before insertion of the IUD by gynecologist.
Insertion of IUD: $\left(\mathrm{TCu}-380 \mathrm{~A}^{\circledR}\right.$, Pregna International Ltd, India).

Post insertion instructions:

Palpation of strings should be performed monthly by the patient.

\section{Statistical analysis:}

Data were entered checked and analyzed using Epi-Info version 6 and SPSS for Windows version 8 (SPSS Inc., Chigaco, USA). Data were summarized using: The arithmetic mean, the Standard Deviation (SD), number and percentage. Mann Whitney-U test, Student t test and X2 (chi-squared) (test of significance). The results were considered significant when the probability of error is less than $5 \%(\mathrm{p}<0.05)$.

\section{RESULTS}

There were no statistically significant differences between both groups as regard age. There was no significant difference between misoprostol group and control group as regard number of previous cesarean sections (CS). The proportion of failed insertion $(0 \%)$ in misoprostol group was statistically significantly lower than placebo group $2 / 60,3.3 \%$ p-value 0.02 (this two cases are previous $3 \mathrm{CSs}$. There was statistically significant difference between both groups regarding difficulty of insertion. The insertion of IUD in misoprostol group was easier than in placebo group; (Table 1).

Table (1): Comparison between the two study groups as regards age, number of CS of studied groups, failed insertion and difficulty of insertion

\begin{tabular}{|l|c|c|c|}
\hline Parameters $\quad$ Groups & $\begin{array}{c}\text { Misoprostol group } \\
(\mathbf{n = 6 0})\end{array}$ & $\begin{array}{c}\text { Control group } \\
(\mathbf{n = 6 0})\end{array}$ & p-value \\
\hline Age (years), Median (Range) & $30(25-40)$ & $29(27-38)$ & $>0.05^{\ddagger}$ \\
\hline Number of previous CS & $29(48.3 \%)$ & $28(46.7 \%)$ & $>0.05^{*}$ \\
1 CS & $31(51.7 \%)$ & $32(53.3 \%)$ & \\
2 CS or more & $0(0.0 \%)$ & $2(3.3 \%)$ & $>0.05^{*}$ \\
\hline Failed insertion & $4(1-7)$ & $5(2-9)$ & $<0.05^{\ddagger}$ \\
\hline Difficulty of insertion & $3.2 \pm 0.6$ & $4.6 \pm 0.7$ & $<0.001^{\bullet}$ \\
Total, Median (Range) & $5.94 \pm 1.3$ & $6.7 \pm 1.8$ & $<0.001^{\bullet}$ \\
1CS, Mean \pm SD & &
\end{tabular}

†: Mann-Whitney test; *: Chi-square test; $\bullet$ : Independent t-test 
Side effects following sublingual administration of misoprostol or placebo before insertion of IUD:

There were statistically significant differences between both groups as regard abdominal cramp, nausea and fever occurring more in misoprostol group before insertion of IUD. There were no statistically significant differences between both groups as regard headache and diarrhea. There was statistically significant differences between both groups regarding pain score with pain scoreless $(5.7 \pm 1.4)$ in misoprostol group, than placebo group $(6.5 \pm 0.9)$, p-value is 0.001; There were no statistically significant differences between both groups regarding other complicationsas syncope, perforation and heavy bleeding, Table (2).

Table (2): Comparison between the two study groups as regards side effects following sublingual administration of misoprostol or placebo before insertion of IUD and mean of pain score

\begin{tabular}{|c|c|c|c|}
\hline Parameters $\quad$ Groups & $\begin{array}{l}\text { Misoprostol group } \\
\quad(\mathbf{n}=\mathbf{6 0})\end{array}$ & $\begin{array}{l}\text { Placebo group } \\
\quad(\mathbf{n}=\mathbf{6 0})\end{array}$ & p-value \\
\hline $\begin{array}{l}\text { Side effects } \\
\text { Abdominal cramp } \\
\text { Headache } \\
\text { Nausea } \\
\text { Diarrhea } \\
\text { Fever }\end{array}$ & $\begin{array}{c}26(43.3 \%) \\
8(13.3 \%) \\
5(8.3 \%) \\
3(5.0 \%) \\
3(5.0 \%) \\
\end{array}$ & $\begin{aligned} & 19(31.6 \%) \\
& 4(6.6 \%) \\
& 1(1.7 \%) \\
& 1(1.7 \%) \\
& 0(0.0 \%)\end{aligned}$ & $\begin{array}{l}>0.05^{*} \\
>0.05^{*} \\
>0.05^{*} \\
>0.05^{*} \\
<0.05^{*}\end{array}$ \\
\hline Mean of pain score & $5.7 \pm 1.4$ & $6.5 \pm 0.9$ & $<0.001^{\bullet}$ \\
\hline $\begin{array}{lll}\text { Complications } & \text { related } & \text { to } \\
\text { IUD insertion } & & \\
\text { Syncope } & & \\
\text { Perforation } & & \\
\text { Heavy bleeding } & & \\
& \end{array}$ & $\begin{array}{l}2(3.3 \%) \\
0(0.0 \%) \\
1(1.7 \%)\end{array}$ & $\begin{array}{l}1(1.7 \%) \\
1(1.7 \%) \\
2(3.3 \%)\end{array}$ & $\begin{array}{l}>0.05^{*} \\
>0.05^{*} \\
>0.05^{*}\end{array}$ \\
\hline
\end{tabular}

\section{DISCUSSION}

Misoprostol, a prostaglandin E1 analogue marketed as a gastrointestinal mucosal protective agent, is safe, effective and inexpensive for use in cervical ripening and labor induction (Speroff and Darney, 2010).

Misoprostol is an effective agent that can be used to increase cervical effacement and dilation and to stimulate uterine contractions. Though it has wide distribution in the United States and many countries, it is not licensed for labor induction and not approved by the FDA for use as a cervical ripening or labor induction agent, making its continued use controversial. Its FDA approved labeling is for use with gasteric ulcer disease for its non- steroidal anti-inflammatory properties, dinoprostone is a long-standing pre induction cervical ripening agent, so it is the only preparation approved by (FDA) for this purpose (Naghshineh et al., 2015).

Vaginally-applied misoprostol is an effective cervical ripening agent in term pregnancies and had been validated in multiple trials. Optimal dose, regimen and route of administration are not clearly established. In terms of cost, misoprostol is a very attractive product (Speroff and Darney, 2010). 
Misoprostol was suggested a cervical ripeninig agent in gynecological uses as prior to hysteroscopy and recently prior to IUD insertion.

Preutthipan and Herabutya (2010), showed that misoprostol, resulted in effective cervical priming before hysteroscopy in non-pregnant woman. They reported greater cervical dilation, decreased cervical resistance, and less need for mechanical dilatation before hysteroscopy or curettage with oral or vaginal misoprostol.

Misoprostol has also been shown to induce cervical dilatation in non-pregnant women when used prior to a hysteroscopy by another older study (Saha et al., 2015).

Our study showed that pretreatment with misoprostol reduced the number of failed insertions and complications during IUD insertion. Moreover, pain during insertion was improved by misoprostol. Difficulty of insertion was estimated in regard to the resistance of the cervix.

A facilitating effect of misoprostol on IUD insertion was found, with significantly less resistance of the internal cervical os, and technically less difficult insertions compared with the untreated controls. This indicated that the insertions were overall easier and more uncomplicated in cases of misoprostol group.

There were two insertions failed due to very narrow cervix in the control group. None of the insertions failed in the misoprostol group.

Side-effects (of which abdominal cramping was the most predominant) occurred in $43.3 \%$ of participants using misoprostol and in $31.6 \%$ using placebo.
The overall number of side-effects of misoprostol gathered in our study was in line with those from another study (Naghshineh et al., 2015).

This study showed a positive effect of administration of misoprostol. This study results agree with results of Scavuzzi et al. (2013) and Bahamondes (2015).

Zapata et al (2016), concluded that misoprostol facilitate insertion of IUD in woman with narrow cervical canal. They investigated the use of sublingual misoprostol one hour prior to insertion of a copper-IUD among nulliparous women. Their low number of failed insertions corresponded with our figure. IUD insertion in nulliparous women who used sublingual $200 \mu \mathrm{g}$ misoprostol and 100 $\mathrm{mg}$ diclofenac was significantly easier than in women who used $100 \mathrm{mg}$ diclofenac alone (one hour prior to IUD insertion). The study showed that misoprostol can be used to facilitate the insertion of an IUD in nulliparous women with a narrow cervix. However, the majority of insertions were uncomplicated and the difficulties few in both groups. Shivering was more common in the misoprostol group. The authors suggested that, this could be reduced by using the vaginal route of misoprostol administration.

Scavuzzi et al. (2013) found less difficulty in inserting IUD in misoprostol group.

Bahamondes et al. (2015) found that pretreatment with intravaginal $100 \mathrm{mcg}$ of misoprostol after IUD insertion failure in patients 4-10 hours before 2nd attempt was significantly better than placebo. 
Dijkhuizen et al. (2011) conducted a RCT aiming to investigate whether pretreatment with misoprostol facilitates the insertion of an IUD in nulli- and multiparous women and failed to show difference for use of misoprostol prior to IUD insertion about insertion failure incidence misoprostol and placebo groups. However, that study was conducted on heterogeneous group of patients both multiparous and nulliparous. This may indicate that misoprostol may be beneficial only in subset of patients like our patients with previous cesarean section or patients with previous failed insertion of IUD.

Swenson et al. (2012) estimated the effects of self-administered misoprostol compared with placebo is 108 patients before intrauterine device (IUD) insertion in women. They failed to show difference in easiness of insertion of IUD with prior use of misoprostol. However this study was not blinded for doctors or patients. More over self-administration misoprostol vaginally may not be effective. These small tablets are better administrated as deep as possible by gynecologist.

Ibrahim and Sayed Ahmed (2013) investigated sublingual $400 \mathrm{mcg}$ misoprostol administered one hour before intrauterine Device (IUD) insertion reduces failed insertions, insertion-related complications and pain in parous women delivered only by elective caesarean section (CS) and found that sublingual administration of misoprostol doesn't facilitate the procedure. But the misoprostol was given in this study 1 hour only before procedure which may not be effective to soften the cervix.
Espey et al. (2014) found that misoprostol does not decrease pain or improve the ease of insertion. But this study was performed only on nulliparous women using only $400 \mathrm{mcg}$ misoprostol.

\section{CONCLUSION}

Our results showed that $600 \mathrm{ug}$ sublingual misoprostol given two hours before Tcu 380 A IUD insertion in patients with previous cesarean section (with no prior vaginal delivery) facilitated the insertion of IUD and decreased the failure rate of insertion (primary outcome measure). Our results also suggested that misoprostol before IUD insertion decreased the pain perceived by the patients, but increased incidence of mild side effect as nausea, fever and abdominal cramps before insertion (secondary outcome measures).

\section{REFERENCES}

1. Bahamondes L, Díaz J, Marchi NM, Petta CA, Cristofoletti MD and Gomez G. (2015): Performance of copper intrauterine devices when inserted after an expulsion. Hum Reprod., 10:2917-2918.

2. Daniels $\mathrm{K}$, Daughtery $\mathrm{J}$, Jones $\mathrm{J}$ and Mosher W. (2015): Current contraceptive use and variation by selected characteristics among women aged 15-44, United States, 2011-2013.national health state report 86: P114. Evidence grade: 11- 2.

3. Dijkhuizen K, Dekkers OM, Holleboom CA, de Groot CJ, Hellebrekers BW, van Roosmalen GJ, Janssen CA and Helmerhorst FM. (2011): Vaginal misoprostol prior to insertion of an intrauterine device:an RCT Hum Reprod., 26 (2): 323-9.

4. Espey E, Singh RH, Leeman L, Ogburnt T, Fowler $K$ and Greene $H$. (2014): Misoprostol for intrauterine device insertion in nulliparous women: a randomized 
controlled trial .Am J Obstet Gynecol. 210 (3): 208.e 1-208.e 5 .

5. Ibrahim ZM and Sayed Ahmed WA. (2013): Sublingual misoprostol prior to insertion of a T380A intrauterine device in women with no previous vaginal delivery. Eur J Contracept Reprod Health Care, 18 (4): 300- 8 .

6. Mosher WD and Jones J. (2010): Use of contraception in the United States: 19822008. Vital and health statistics. Series 23, Data from the National Survey of Family Growth., (29): 1- 44.

7. Naghshineh $\mathbf{E}$, Allame $\mathbf{Z}$ and Farhat $\mathbf{F}$ (2015): The effectiveness of using misoprostol with and without letrozole for successful medical abortion: A randomized placebo-controlled clinical trial. Journal of research in medical sciences: the official journal of Isfahan University of Medical Sciences., 20 (6): 585- 9.

8. Peipert JF, Zhao Q, Allsworth JE, Petrosky E, Madden T, Eisenberg D and Secura G. (2011): Continuation and satisfaction of reversible contraception. Obstet Gynecol., 11 7(5): 110513.

9. Preutthipan S and Herabutya $Y$ (2010): Vaginal misoprostol for cervical priming before operative hysteroscopy: a randomized controlled trial. Obstet Gynecol., 96(6), 8904.

10. Saha M, Chakraborty A, Chattopadhyay S, Saha S, Paul J and Das A. (2015): Effect of misoprostol for cervical priming before gynecological procedures on no pregnant premenopausal women. Journal of natural science, biology, and medicine, 6 (Suppl 1): S123-S127.

11. Scavuzzi A, Souza AS, Costa AA and Amorim MM. (2013): Misoprostol prior to inserting an intrauterine device in nulligravidas: A randomized controlled trial . Hum Reprod., 28 (8): 2118 -25.
12. Speroff L and Darney PD (2010): Intrauterine contraception. In. A Clinical Guide for Contraception. (eds) Lippincott Williams \& Wilkins, Philadelphia P.A 19106 USA. (4th ed) ch.7. P: 219.

13. Swenson C, Turok DK, Ward K, Jacobson JC and Dermish A. (2012): Self administrated misoprostol or placebo before intrauterine device insertion in nulliparous women: a randomized controlled trial. Obstet Gynecol., 120 (2pt 1): 341-7.

14. Trussell J. (2010): Update on the cost effectiveness of contraceptives in the United States. Contraception. 82(4): 391- 396.

15. Trussell J, Nelson A, Cates W, Kowal D and Policar M. (2011): "Emergency contraception". In: Hatcher, Robert A.; Trussell, James; Nelson, Anita L.; Cates, Willard Jr.; Kowal, Deborah; Policar, Michael S. Contraceptive technology $\left(20^{\text {th }}\right.$ revised ed.). New York: Ardent Media. pp. 113-145.

16. Zakiyah N, van Asselt AD, Setiawan D, Cao $Q$, Roijmans $F$ and Postma MJ (2019): Cost-Effectiveness of Scaling Up Modern Family Planning Interventions in Low-and Middle-Income Countries: An Economic Modeling Analysis in Indonesia and Uganda. Applied health economics and health policy, 17(1): 65- 76.

17. Zapata LB, Jatlaoui TC, Marchbanks PA and Curtis KM. (2016): Medications to ease intrauterine device insertion: a systematic review. Contraception, 94(6): 739- 59. 


\section{إنضاج عنق الرحم باستخدام أقراص الميزوبرستول تحت

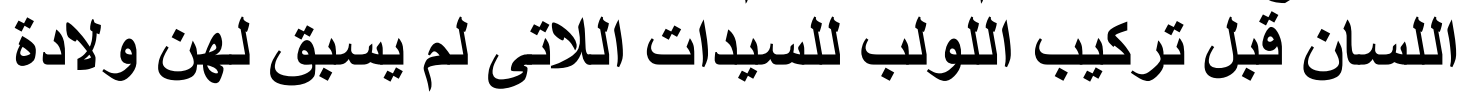 طبيعية}

\section{إسماعيل محمد الجارحى، ماجد محمد لبيب*، محمد على جلال}

قسمي النساء و التوليد، كلية الطب، جامعة الأزهر ومستثفى المعادى للقوات المسلحة المصرية*

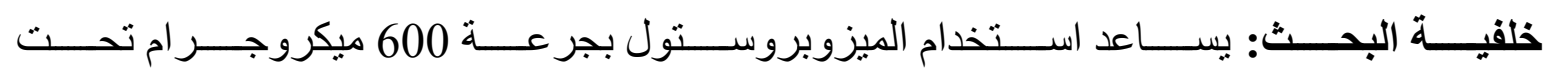

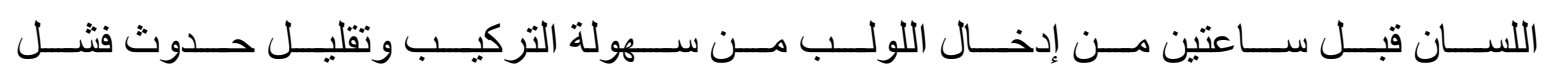

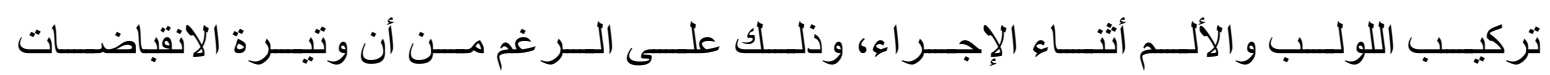
زادت بعد استخدام الميزوبروستول.

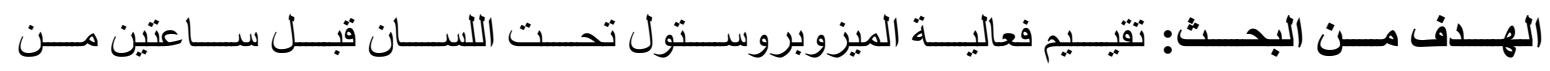
إدخال اللولب الرحمي لدى النساء الخاضعات لعمليات قيصرية سابقة.

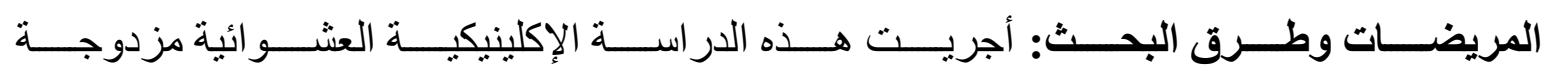

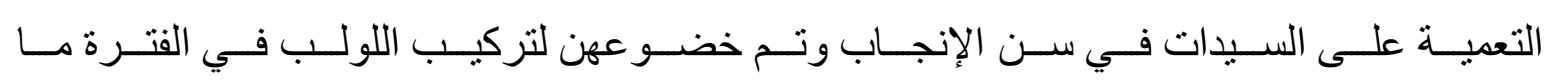

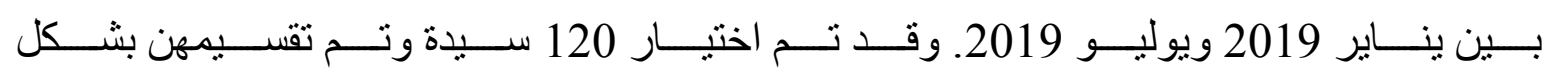

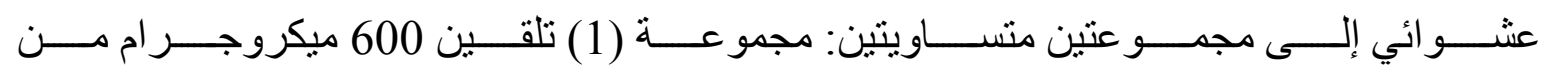

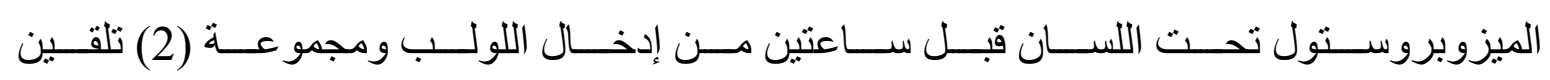
العلاج الوهمي.

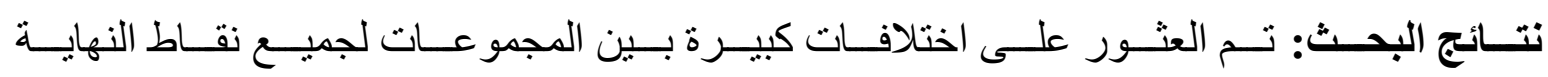

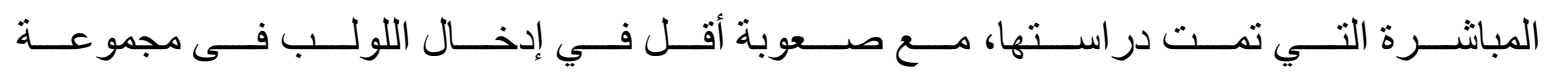

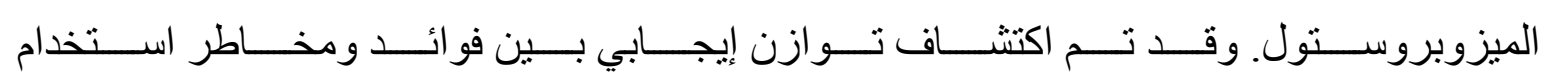

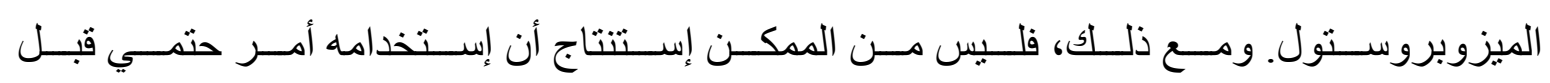

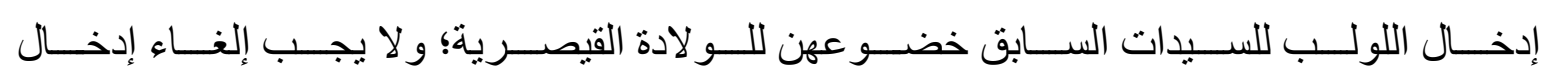
اللولب عند عدم تو افر الدواء.

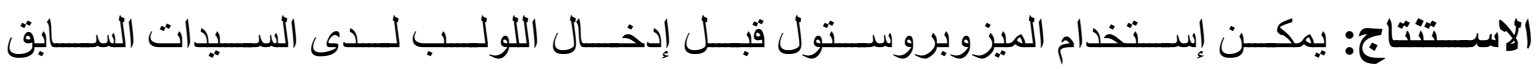
خضو عهن لو لادة قيصرية سابقة. 